\title{
Central bank statistics as part of official statistics: The case of the European System of Central Banks (ESCB)
}

\author{
Aurel Schubert \\ Vienna University of Economics and Business, Welthandelsplatz 1, 1020 Vienna, Austria \\ E-mail: aurel.schubert@wu.ac.at
}

\begin{abstract}
Responsibility for statistics at the level of the European Union is shared between the European Central Bank (ECB) and the European System of Central Banks at the one hand, and the European Commission (Eurostat) and the European Statistical System (consisting of the national statistical institutes) at the other hand.

This paper addresses the rationale, the legal basis as well as the practical organisation of this "twin-towers" approach of European statistics, with central bank statistics well inside the boundaries of official statistics in Europe. It shows the respective fields of competences, and their distribution based on comparative advantages, as well as the - growing - areas and forms of cooperation. Finally, the current challenges, both those that are central bank statistics specific but also those (many) that are common to both systems are being touched upon. A special emphasis is given to the role of statistics for modern central banking ("evidence - based policy making"), in the areas of monetary policy, financial stability as well as banking supervision. Conclusions after 20 years of experience with this approach are drawn at the end.
\end{abstract}

Keywords: Central Bank Statistics, European System of Central Banks, official statistics, eurosystem, data quality

\section{Introduction}

"Official statistics play a central role in democratic societies as they provide public authorities, policy makers, citizens and users with objective and impartial information to support taking evidence-based decisions and engaging in open debate." (UNECE, Generic Law on Official Statistics)

Central bank statistics are an integral and growing part of official statistics. Modern central banking as we see it in most parts of the world is - in all its functions "evidence based". This applies to monetary policy as well as to financial stability policy, and also to banking supervision and payments systems oversight. Data and statistics are crucial for central bank policy making, for the analysis, for decision making, for communicating the decisions and also for tracking the effects of the policies pursued. With that statistics are central to the transparency and the credibility of central banks and the trust of the people in them.
While central banks use many available official - but increasingly also "big data based" - statistics for their analyses and decision making, they also produce a lot of the required statistics themselves, especially on the financial sector. This immediate policy relevance gives special importance as well as responsibility to central bank produced statistics. Central bank statisticians take this responsibility very seriously, applying all aspects of "best practices" to the collection, production, quality controls, dissemination and communication of central bank statistics.

A very good example for this increasing role of central bank statistics and for the cooperation with the other producers of official statistics, usually the national statistical institutes, is the European Union, and specifically the Euro Area, i.e. the countries that have adopted the euro as their common currency.

An elaborate system of collaboration has been set up within the European Union, between Eurostat and the European Statistical System (ESS) on the one hand 
and the European Central Bank (ECB) and the European System of Central Banks (ESCB) on the other hand. During the now more than 20 years of European Economic and Monetary Union, this system has been further developed and enhanced. A lot of experience has been gained, an experience worth to be shared with other parts of the world (of statistics).

But central bank statistics - especially but not exclusively in Europe - are also used far beyond central banks, by other policy making bodies and institutions, and by the civil society. They are - after all - a public good, financed by public money.

\section{Why do central banks need their own statistical system?}

"Nothing is more important for monetary policy than good statistics" (A.Lamfalussy, 1996)

As far as statistics are concerned, central banks are "Janus-faced"; they are power users as well as important producers of statistics. They are important players on both sides of the "statistics market", the demand side as well as the supply side.

Central banks need a lot of high-quality data for their decision-making processes. Central banking is evidence-based policy making. Therefore, central banks are big users of all kinds of economic and financial statistics. At the same time, they are also important producers of statistics, mainly-but not exclusively - on the financial sector.

Their dependence on very timely and very specific data, often almost real-time data, makes it important that they are not totally dependent on the strategies, priorities and operations of other data producers that might follow very different priorities and policies. The agility required from central bank decision making and policy implementation requires a reliable flow of the relevant data, also covering at short notice newly arising financial phenomena. Agility in the provision of relevant statistics is crucial for the agility in the policy making that is necessary for and expected from modern central banks. Almost every day, new financial products are being created, new financial institutions enter the markets and even new markets are created. Central banks have to follow these developments in real time, have to determine the relevance of these new developments (usually via preliminary data collections) and - if determined as policy relevant - start regular data collections and the production of such statistics. This requires the existence of their own statistical legal powers as well as of their own statistics departments, collection systems and production processes.

This allows central banks to react quickly in times of new data needs and to be independent of any political decision-making processes which often last for years before decisions are made.

The main purpose of the European statistics developed, produced and disseminated by the European Central Bank (ECB) is to support the monetary and macroprudential policy-making and supervisory functions of the ECB, as well as the other tasks of the Eurosystem and the European System of Central Banks (ESCB). These include giving statistical support to the European Systemic Risk Board (ESRB) and providing data and related services to other public authorities, financial market participants, the media and the general public.

\subsection{The twin-towers of European statistics}

The production of European statistics is organised around two separate pillars, the ESCB and the ESS partnership, with separate legal frameworks and governance structures. The ESCB is a fully fledged system enshrined in the Treaty on the Functioning of the European Union (TFEU). ${ }^{1}$ It is composed of the European Central Bank (ECB) and the National Central Banks (NCBs); the ECB's Governing Council is its highest decision-making body.

According to its statute ${ }^{2}$, the ECB, assisted by the national central banks (NCBs), may collect the statistics necessary to undertake the ESCB's tasks, including for monetary policy and financial stability purposes, either from the competent national authorities or directly from economic agents.

The members of the ESCB and the ESS need to cooperate closely to maximise synergies, minimise the reporting burden and ensure the production of complete and coherent European statistics. ${ }^{3}$ To facilitate this cooperation, the quality frameworks of the ESCB and the ESS have been closely aligned. The ESCB public commitment on European statistics ${ }^{4}$ and the ESS Code of

\footnotetext{
${ }^{1}$ EU, Treaty on the European Union and the Functioning of the European Union, https://www.ecb.europa.eu/ecb/legal/pdf/oj _c_2016_202_full_en_txt.pdf.

${ }^{2}$ EU, Protocol on the Statute of the European System of Central Banks and of the European Central Bank, https://www. ecb.europa.eu/ecb/legal/pdf/en_statute_2.pdf

${ }^{3}$ See ECB (2015). "European statistics: cooperation between the European System of Central Banks and the European Statistical System", Economic Bulletin, Issue 7.

${ }^{4}$ ECB, Public commitment on European Statistics by the ESCB.
} 
Practice $^{5}$ set out almost identical statistical principles for the development, production and dissemination of European statistics.

The ECB works closely with the other institutions of the European Union, particularly with Eurostat (the statistical office of the European Union). The precise division of labour is set out in the Memorandum of Understanding on Economic and Financial Statistics of March 2003. ${ }^{6}$ Moreover, the ESCB and the ESS cooperate in the production of European statistics under their separate legal frameworks and their respective spheres of competence. A Memorandum of Understanding between the ESS and the ESCB of April $2013^{7}$ strengthened this cooperation in areas of shared responsibility and/or common interest.

The competence to collect statistics is shared, in certain fields, with the ESS operating on the basis of Regulation (EC) No 223/2009 of the European Parliament and of the Council of 11 March 2009 on European statistics. Both Regulation (EC) No 2533/98 and Regulation (EC) No 223/2009 require the ESS and the ESCB to cooperate closely with a view to minimising the reporting burden and guaranteeing the coherence necessary to produce European statistics.

Accordingly, in line with the Memorandum of Understanding on Economic and Financial Statistics of March 2003 between the Directorate General Statistics of the ECB and the Commission's Statistical Office (Eurostat), monetary, financial markets and institutions statistics are primarily the ECB's responsibility, while general economic statistics are primarily the responsibility of the Commission (Eurostat). The two institutions share statistical responsibility, e.g. in relation to the balance of payments, and for quarterly financial and non-financial accounts for institutional sectors. Institutional cooperation between the ESCB and the ESS is further strengthened through the operation of the Committee on Monetary, Financial and Balance of Payments Statistics (CMFB), which is composed of both ESCB and ESS members and assists the Commission in drawing up and implementing the multiannual programme of work relating to monetary, financial and balance of payments statistics.

\footnotetext{
${ }^{5}$ European Statistics Code of Practice (2017).

${ }^{6}$ Memorandum of Understanding on economic and financial statistics between the Directorate General Statistics of the ECB (DG Statistics) and the Statistical Office of the European Communities (Eurostat) 10.3.2003.

${ }^{7}$ Memorandum of Understanding on the Cooperation between the Members of the European Statistical System and the Members of the European System of Central Banks, 24 April 2013.
}

In addition, cooperation of the ESCB with the ESS has been strengthened by the establishment of the European Statistical Forum (ESF) by way of a Memorandum of Understanding between the ESCB and the ESS of April 2013. ${ }^{8}$

\subsection{Strong legal basis for the statistical competences of the $E C B$}

The Treaty on the functioning of the European Union$^{9}$ gives the ESCB/ECB strong statistical powers, thus establishing two complementary statistical systems in the European Union. In order to avoid any overlaps, these powers are restricted to the collection of data on the financial sector.

Article 5 of the statutes ${ }^{10}$ specifies

5.1. In order to undertake the tasks of the ESCB, the $\mathrm{ECB}$, assisted by the national central banks, shall collect the necessary statistical information either from the competent national authorities or directly from economic agents. For these purposes it shall cooperate with the Union institutions, bodies, offices or agencies and with the competent authorities of the Member States or third countries and with international organisations.

5.2. The national central banks shall carry out, to the extent possible, the tasks described in Article 5.1.

5.3. The ECB shall contribute to the harmonisation, where necessary, of the rules and practices governing the collection, compilation and distribution of statistics in the areas within its fields of competence. 5.4. The Council, in accordance with the procedure laid down in Article 41, shall define the natural and legal persons subject to reporting requirements, the confidentiality regime and the appropriate provisions for enforcement.

According to its statutes, the ECB, assisted by the NCBs, may collect the statistics necessary to undertake the ESCB's tasks, including monetary policy and financial stability purposes, either from the competent national authorities or directly from economic agents. The data collected may also be used for banking supervisory purposes.

This gives the ECB the powers of a European law maker, also in the area of statistics. Based on that, the

\footnotetext{
${ }^{8}$ See footnote 6 .

${ }^{9}$ See footnote 1 .

${ }^{10}$ See footnote 2 .
} 
Two pillars for European economic and financial statistics

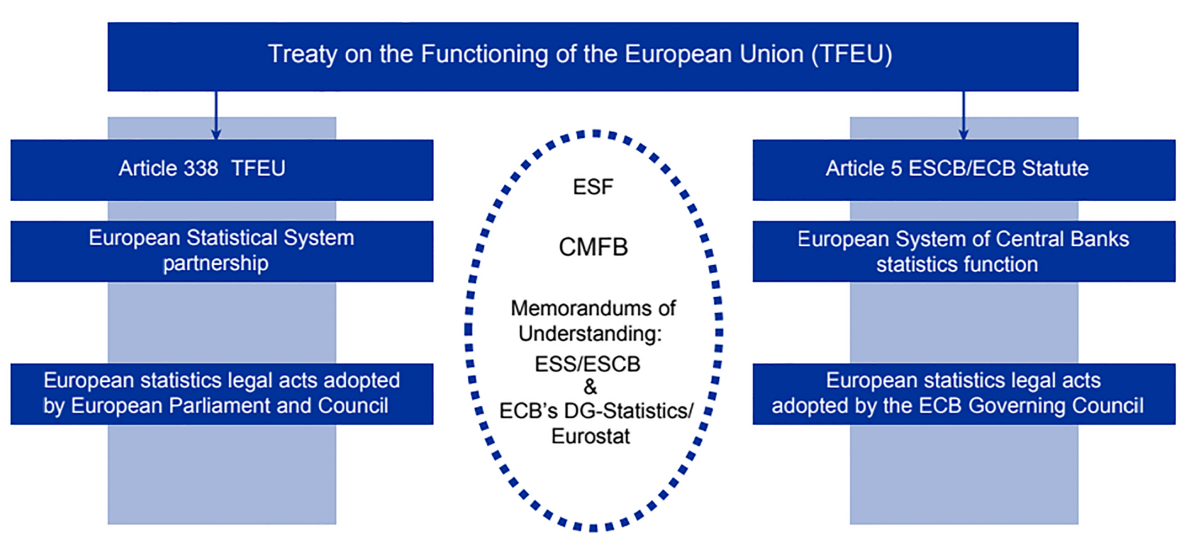

Fig. 1. Two pillars for European economic and financial statistics.

ECB has adopted and published a number of legal acts addressing a wide range of statistics.

Article 338 of the Treaty recognises the role and powers of the ESCB in the field of statistics by providing that when the Council of the European Union adopts measures for the production of statistics necessary for the performance of the tasks of the EU, such measures should be without prejudice to Article 5 of the Statute of the ESCB.

Further details of the ECB's mandate for data collection are set out in Council Regulation (EC) No 2533/98 of 23 November 1998 concerning the collection of statistical information by the European Central Bank. According to Article 2(1) thereof, the particular areas of ESCB statistical competence include monetary and financial statistics, banknote statistics, payments and payment systems statistics, financial stability statistics, balance of payments statistics and international investment position statistics. Regulation (EC) No 2533/98 further defines the reference reporting population for the ESCB statistics (Article 2), confidentiality regime (Articles 8, 8a, 8b, 8c and 8d) and enforcement (Article 7) and gives the ECB the power to adopt regulations for the definition and imposition of its statistical reporting requirements (Article 5(1)).

\subsection{What kind of statistics does the ESCB/Eurosystem produce?}

The ECB's monetary policy strategy is very data intensive. The monetary analysis which forms the basis for the decision making is organised in two pillars, the "economic analysis" and the "monetary analysis".

While most of the data for the economic analysis mainly general economic data - come from Eurostat sources, the monetary analysis largely builds on $\mathrm{E}(\mathrm{S}) \mathrm{CB}$ statistics. The ECB works closely with Eurostat in order to develop harmonised statistical concepts and achieve high-quality general economic statistics for the euro area and its Member States with the necessary frequency and timeliness. The ECB itself compiles and disseminates various derived indicators for the euro area (such as measures of residential and commercial property prices, industrial new orders, employment and productivity) and calculates seasonally and calendaradjusted data for selected indicators.

Statistics produced by the ECB are largely financial but also some economic statistics, such as money and banking (including interest rates) statistics, banknotes statistics, payments and payment systems statistics, financial stability statistics, balance of payments statistics and international investment positions statistics.

The core of the statistics produced and published by the ECB are monetary statistics and statistics relating to financial institutions and markets. Monetary aggregates and their counterparts are calculated from the aggregated balance sheet of the Monetary Financial Institutions (MFI) sector, which is also published on a monthly basis. MFIs are institutions - such as banks and money market funds - that take deposits or issue securities, and grant credit and/or invest in securities on their own account. MFI balance sheet statistics are also used to calculate the minimum reserve requirements that credit institutions must fulfil for monetary policy purposes.

To provide comprehensive statistical coverage of the financial sector, and thus enrich monetary and financial stability analyses, the ECB also publishes information on financial institutions outside the MFI sector, such as 
investment funds (other than money market funds) and financial vehicle corporations (securitisation vehicles). The ECB and the NCBs publish lists of these three groups of institutions via the register RIAD (see below).

The ECB also compiles harmonised statistics on the interest rates applied by MFIs for loans to and deposits from euro area households and firms. From these statistics, the related cost of borrowing indicators are derived.

The ECB produces detailed statistics on financial markets, including monthly data on volumes of debt securities and quoted shares and information on the prices of financial instruments. It also publishes euro area government bond yield curves daily.

The ECB produces and publishes a monthly balance of payments (b.o.p.) for the euro area, showing the main transactions between euro area residents and residents of countries outside the euro area. The monthly b.o.p. is supplemented by more detailed quarterly statistics, which feature a geographical breakdown. ${ }^{11}$

In addition, the ECB publishes monthly statistics on the international reserves and foreign currency liquidity of the ECB and the Eurosystem. It also publishes quarterly statistics on the international investment position (i.i.p.) of the euro area, which provides a picture of the euro area's claims and liabilities vis-à-vis the rest of the world, together with a detailed geographical breakdown.

One of the many lessons of the Great Financial Crisis of 2008/09 was that the euro area is much more heterogenous than planned and expected. The economic situation and developments among the participating countries are very diverse, but also within the different economic sectors there is a very large and often increasing heterogeneity. In order to analyse and understand this divergence and its economic policy relevance, an urgent need for more granular information arose. ${ }^{12}$ Central bank statisticians reacted by engaging in several granular data projects, for securities holding statistics, for loan-by-loan data ("AnaCredit") and for more information on the money marke ("MMSR")t. These are important new information sources for monetary policy, financial stability policy as well as for banking supervision.

\footnotetext{
${ }^{11}$ Some NCBs also produce national statistics which the ECB does not produce for the euro area, like for instance trade in services statistics for their respective countries.

${ }^{12}$ In addition to the need for more granular data, also many of the "traditional" statistics - like the b.o.p. - need further enhancements. These enhancements are already being pursued in parallel to the new granular data collections.
}

Since September 2009 the ECB has conducted a biannual survey on the access to finance of small and medium-sized enterprises (SMEs) in Europe, in cooperation with the European Commission. The survey intends to capture those enterprises' financing needs, the structure of financing and the availability of finance. The results of this survey are broken down, for example, by size of firm, by type of economic activity, by euro area country and by age of firm.

The ECB also coordinates a triennial survey on euro area households' finance and consumption, in collaboration with the Eurosystem and in close cooperation with national statistical institutes delivering detailed information on household debt and wealth by country, age groups, educational achievements etc. Aggregate distributional indicators for the euro area are also published.

In addition, the ECB maintains several registers as the backbone for statistical data collections. RIAD and CSDB are the most important ones. The Centralised Securities Database (CSDB) is a single information technology infrastructure, operated jointly by the members of the ESCB, including NCBs of noneuro area Member States where such NCBs voluntarily participate in the operation of the CSDB. The CSDB receives and stores item-by-item data, in particular data on securities, their issuers and prices. RIAD is the Register on Institutions and Affiliates, covering all relevant financial institutions and even non-financial companies in the context of the granular loan-by-loan data base.

The ECB is also in charge of providing statistical support to the European Systemic Risk Board in accordance with Council Regulation (EU) No 1096/2010 of 17 November 2010 conferring specific tasks upon the European Central Bank concerning the functioning of the European Systemic Risk Board (ESRB). In particular, it produces and publishes the ESRB's Risk Dashboard, a set of quantitative and qualitative indicators of systemic risk in the EU financial system. ${ }^{13}$

\subsection{Organisation of ESCB statistics}

The ECB collects the statistical data, assisted by the NCBs and with the support of the ESCB's Statistics Committee (STC). The STC is chaired by the Director General for Statistics of the ECB and brings together the Directors of Statistics of the NCBs. It coordinates the preparation of all new ESCB statistics, supported

\footnotetext{
${ }^{13}$ See https://www.esrb.europa.eu/pub/rd/html/index.en.html
} 
by several working groups of statistical domain experts. The ECB then produces the statistics, conducts quality assurance and disseminates them in conformity with the statistical principles of impartiality, objectivity, professional independence, cost-effectiveness, statistical confidentiality, minimisation of the reporting burden and high output reliability. These statistical principles are reflected in the ESCB's public commitment on $\mathrm{Eu}-$ ropean statistics. ${ }^{14}$

The NCBs (and, in some cases, other national authorities) collect data from monetary financial institutions (MFIs), other financial intermediaries, and other reporting agents and sources in their respective countries. They aggregate the data at the national level and send these data to the ECB, which then compiles and disseminates the aggregates and the underlying national data for the euro area.

\subsection{Strong independence as a core characteristic}

The independence of the ESCB when producing its statistics is guaranteed in its statute as well as in the Treaty provisions. ${ }^{15}$ It is the sole responsibility of the Governing Council of the ECB, as the ESCB's decisionmaking body, to coordinate the statistical activities of the ECB and the NCBs in their capacity as members of the ESCB.

"In accordance with Article 130 of the Treaty on the Functioning of the European Union, when exercising the powers and carrying out the tasks and duties conferred upon them by the Treaties and this Statute, neither the ECB, nor a national central bank, nor any member of their decision-making bodies shall seek or take instructions from Union institutions, bodies, offices or agencies, from any government of a Member State or from any other body. The Union institutions, bodies, offices or agencies and the governments of the Member States undertake to respect this principle and not to seek to influence the members of the decision-making bodies of the ECB or of the national central banks in the performance of their tasks." (Article 7, Statutes)

\section{Cooperation fora between ESCB and ESS}

"If the central bank is in charge of key statistics in the country, close cooperation and coordination of

\footnotetext{
${ }^{14}$ See footnote 4.

${ }^{15}$ See Recital 24 of Regulation (EU) No 2015/759.
}

statistical work with the National Statistical Office is crucial."16

The members of the ESCB and the ESS need to cooperate closely to maximise synergies, minimise reporting burden and ensure the production of complete and coherent European statistics. ${ }^{17}$ The main tools for this close cooperation on an operational level is the Committee on Monetary, Financial and Balance of Payments Statistics (CMFB). ${ }^{18}$

In addition, cooperation of the ESCB with the ESS has been strengthened by the establishment of the European Statistical Forum (ESF) by way of a Memorandum of Understanding between the ESCB and the ESS of 24 April 2013. The ESF allows strategic cooperation in areas of common interest, facilitating the handling of individual issues by the CMFB and other relevant substructures of the two systems.

The ESCB and the ESS are taking together a leading role in global statistical projects, such as the IMF's Special data Dissemination Standard Plus (SDDS+) and the G-20 Data Gaps Initiative.

\subsection{Quality commitment and quality assessment}

While the ESCB and the ESS operate under separate legal frameworks that reflect their respective governance structures, they follow the same statistical principles and apply very similar statistical quality assurance procedures. This alignment of the quality frameworks aims to ensure the same quality standards apply to both sets of European statistics.

In line with the mission statement of the Eurosystem, ${ }^{19}$ the ECB is committed to adhering to values such as credibility, trust, transparency and accountability, which underpin the integrity of the statistical function provided by the Treaty on the Functioning of the European Union (Article 5 of the Statute of the European System of Central Banks and of the European Central Bank). Adherence to high-quality statistical standards is a key factor in maintaining the public's confidence in ESCB statistics, upon which monetary policy decisions and other Eurosystem tasks are based. It also ensures the comparability of euro area and national statistics at the international level. In the performance of its statistical

\footnotetext{
${ }^{16}$ UNECE (2016), p.26

${ }^{17}$ Article 9 of Regulation (EC) No 223/2009 and Article 2(a) of Regulation (EC) No 2533/98.

${ }^{18}$ See https://www.cmfb.org/.

${ }^{19}$ Mission Statement of the Eurosystem, https://www.ecb.europa. eu/ecb/orga/escb/eurosystem-mission/html/index.en.html.
} 
function, the ESCB is committed to good governance and the highest ethical standards, as well as to executing its tasks in a spirit of cooperation and teamwork.

The ECB attaches great importance to the quality of its statistics while keeping the reporting burden to a minimum for respondents. As stated in the Public commitment on European Statistics by the ESCB, available on the ECB website, it takes account of internationally agreed quality standards in the performance of its statistical function and is committed to good governance and the highest ethical standards. It is also committed to conducting its tasks in a spirit of cooperation and teamwork and takes into consideration internationally agreed quality standards and guarantees the confidentiality of information.

In addition, the ECB has the powers to enforce its reporting requirements and their quality, even with the support of financial sanctions.

\subsection{Public commitment on European Statistics by the ESCB}

The ESCB's statistical function is based on a legal mandate to collect all necessary and relevant data in order to produce and disseminate impartial, reliable, appropriate, timely, consistent and accessible statistics in the areas under the ESCB's responsibility. Where appropriate, these statistics comply with European and internationally agreed standards, guidelines and good practices. The independence granted to the ESCB under Article 130 of the Treaty on the Functioning of the European Union entails, among other things, that there is no political interference in the compilation and dissemination of statistical information.

The ESCB takes into consideration internationally agreed quality standards, such as those formulated in the IMF's Special Data Dissemination Standard ${ }^{20}$ and Data Quality Assessment Framework, which are in turn rooted in the UN's Fundamental Principles of Official Statistics. ${ }^{21}$ Without prejudice to the Protocol on the Statute of the European System of Central Banks and of the European Central Bank, it collaborates with the European Statistical System (ESS), and takes account of the principles laid down in the European Statistics Code of Practice for the National and Community Statistical Authorities.

In order to formalize this commitment to the highest quality, the ESCB has adopted, published and adheres

\footnotetext{
${ }^{20}$ See https://dsbb.imf.org/sdds-plus/overview.

${ }^{21}$ See https://unstats.un.org/unsd/dnss/gp/fundprinciples.aspx.
}

to the "Public commitment on European Statistics by the ESCB". 22

The ESCB aims to perform its statistical function effectively and to use resources efficiently when collecting, compiling and disseminating statistics. In accordance with primary and secondary EU law (Article 130 of the Treaty and Article 5 of the Statute, and Council Regulation 2533/98 as amended by Council Regulation $951 / 2009$ respectively), the aim is to collect the necessary statistical information of an appropriate quality while keeping the reporting burden on respondents to a minimum, guaranteeing their privacy and protecting the confidentiality of the non-public information they provide. In addition, the ESCB guarantees that confidential statistical information provided by an ESS authority is used for statistical purposes only.

In short, and in line with the Eurosystem Mission Statement, ${ }^{23}$ ESCB statistics are governed by a set of principles referring to the ESCB's institutional environment, statistical processes and statistical output.

Quality reports on specific statistical domains are produced and also published by the ECB. ${ }^{24}$

Regular audits - basically one each year - of specific statistical products or processes within the ESCB's audit framework support and strengthen the quality assurance process. As such, they serve a similar purpose - albeit with different methodology and frequency - as the Peer Reviews of the ESS, which take place about every five years.

\subsection{Merits and costs procedure (MCP)}

The introduction of new or substantially enhanced regulations on European statistics by the European System of Central Banks (ESCB) is subject to a systematic assessment of the merits and costs of the new data collection. This approach ensures that new statistics are sufficiently justified by high-priority policy needs and it provides incentives to search for the most cost-effective solutions, with the aim to keep the burden placed on the reporting agents to a minimum.

It consists of a number of steps involving (i) ECB internal users, users at the national central banks (NCBs) and the European Commission as well as other EU bod-

\footnotetext{
${ }^{22}$ See https://www.ecb.europa.eu/stats/ecb_statistics/governance_ and_quality_framework/html/escb_public_commitment_on_european _statistics.en.html.

${ }^{23}$ See footnote 14.

${ }^{24}$ See for instance: https://www.ecb.europa.eu/pub/euroareafinanci alaccounts/html/ecb.eaqfa201906 666af2a524.en.html.
} 
ies, who are requested to state, prioritize and justify their requirements; and (ii) compilers of the statistics in the ESCB and beyond and, typically, future respondents or their representative organizations in order to assess the costs of new requirements, with the aim of finding the most cost-effective data collection and ESCB compilation methods.

\subsection{Increased transparency in ECB regulations on European Statistics}

On 4 October 2016 the Governing Council approved principles increasing transparency in developing ECB regulations on European statistics and taking into account the transparency practices of the European Parliament, the Council of the European Union and the European Commission. The ECB impact assessment, which already includes a merits and costs procedure (MCP), is complemented by public consultations on future draft ECB regulations on European statistics. Information on the MCP and the results for the euro area of each future MCP are also published. The first such formal public consultation was performed in the context of the adoption of the ECB Regulation on statistical reporting requirements for pension funds.

\subsection{Dissemination, data access and statistical services}

ESCB/ECB statistics are a public good. Therefore, both the ECB as well as the NCBs spend a lot of efforts in making the data available to the public, via several channels of dissemination and communication.

A wide range of statistics are published in monthly and quarterly press releases as well as in regular electronic publications which can be downloaded from the ECB's website. All these statistics and more can be found in the ECB's Statistical Data Warehouse (http://sdw.ecb.europa.eu) in the "Statistics" section of the ECB's website. Moreover, the ECB enables users to access the main statistics through a statistical mobile tablet app. Detailed documentation on the definitions and concepts used for the various statistics (including all relevant legal acts) is also available on the ECB's website.

The Statistical Data Warehouse (SDW) is the ECB's online data delivery service for statistics. It is intended for a wide range of users of euro area statistics. In addition to the SDW, there is a special webpage, Our Statistics, that gives an easier access to the non-expert users for a limited number of data series, including the possibility for country comparisons and for easy embedding into articles.

\subsection{Common challenges for NCB and NSIs}

In today's world and economy, central bank statisticians and national statistical institutes share many of the same new and future challenges. The increasing speed of globalisation and digitalisation casts doubts on the traditional methodologies and methods of producing (national) economic statistics. New concepts and collection processes are required in order to stay relevant for policy making. One of the many tools to address these challenges would be to rely more than ever on very granular data, very standardised, and combined with modern data sharing arrangements (respecting legitimate confidentiality needs). But these are big leaps to take, requiring changes in laws and regulations, in IT systems, and often also in the basic philosophy of statistical production.

In parallel, producers of official statistics have to cope with a general mood of increasing distrust of the citizens in public and official institutions. This distrust in official statistics opens doors for alternative data producers and for the spread of fake news for political or commercial interests.

Adequate resources and new staff skills are needed to strengthen official statistics and so to build a wall against the misinformation generated by the producers and the distributors of fake news.

\section{Conclusions}

The success of European statistics is largely due to the robust legal framework underpinning the collaboration between the national and European statistical systems. European statistics are produced by two separate but equal pillars, the ESCB, composed of the European Central Bank (ECB) and the national central banks (NCBs) of the EU countries, and the ESS, comprising Eurostat and the national statistical institutes (of the EU and EFTA countries). This close and well-structured cooperation, based on a robust legal framework, could serve other countries and economic areas as a model.

The strong governance of the ESCB as a system under the TFEU has been fundamental to its important contributions to European statistics. Its key features are: (i) full independence when producing European statistics, (ii) the capacity to legislate within the framework set by the Council of the European Union, and (iii) the central role of the ECB's Governing Council in deciding the ESCB statistical programme. As such, the competences, the rules, and the operations of central 
bank statistics in the ESCB are fully in line with the intentions and even the wording of the Generic Law on Official Statistics (UNECE). ${ }^{25}$

Central bank statistics are well inside the borders of official statistics. Actually, they are part and parcel of official statistics as official statistics would be incomplete without all the relevant data central banks produce on the increasingly important financial sector.

\section{Acknowledgments}

I want to thank Per Nymand-Andersen and two anonymous referees for valuable inputs.

\section{References}

[1] Council Regulation (EC) No 2533/98 of 23 November 1998 concerning the collection of statistical information by the European Central Bank.

[2] ECB, Public commitment on European Statistics by the ESCB, https://www.ecb.europa.eu/stats/ecb_statistics/governance_and_ quality_framework/html/escb_public_commitment_on_ european_statistics.en.html.
[3] ECB (2015). "European statistics: cooperation between the European System of Central Banks and the European Statistical System", Economic Bulletin, Issue 7, pp. 71-77.

[4] ECB, Mission Statement of the Eurosystem, https://www.ecb europa.eu/ecb/orga/escb/eurosystem-mission/html/index.en. html.

[5] Eurostat (2017), European Statistics Code of Practice, https:// ec.europa.eu/eurostat/web/quality/european-statistics-codeof-practice.

[6] European Union, Treaty on the European Union and the Functioning of the European Union, https://www.ecb.europa. eu/ecb/legal/pdf/oj_c_2016_202_full_en_txt.pdf.

[7] European Union, Protocol on the Statute of the European System of Central Banks and of the European Central Bank, https://www.ecb.europa.eu/ecb/legal/pdf/en_statute_2.pdf.

8] Memorandum of Understanding on economic and financia statistics between the Directorate General Statistics of the ECB (DG Statistics) and the Statistical Office of the European Communities (Eurostat), 10 March 2003.

[9] Memorandum of Understanding on the Cooperation between the Members of the European Statistical System and the Members of the European System of Central Banks, 24 April 2013.

[10] UNECE (2016), Generic Law on Official Statistics for Eastern Europe, Caucasus and Central Asia, United Nations.

\footnotetext{
${ }^{25}$ See UNECE, Generic Law on Official Statistics for Eastern Europe, Caucasus and Central Asia, United Nations, 2016.
} 